\title{
Counter-ion effect on surfactant-DNA gel particles as controlled DNA delivery systems
}

\author{
M. Carmen Morán ${ }^{1, *}$, Tania Alonso ${ }^{1}$, Filipe S. Lima ${ }^{2}$, M. Pilar Vinardell ${ }^{1}$, \\ M. Graça Miguel ${ }^{3}$ and Björn Lindman ${ }^{3,4}$ \\ ${ }^{1}$ Departament de Fisiologia, Facultat de Farmàcia, Universitat de Barcelona, Avda. \\ Joan XXIII, 08028 Barcelona, Spain. \\ ${ }^{2}$ Instituto de Química, Universidade de Sao Paulo, SP, Brazil. \\ ${ }^{3}$ Department of Chemistry, University of Coimbra, Rua Larga, 3004-535 Coimbra, \\ Portugal. \\ ${ }^{4}$ Physical Chemistry 1, University of Lund, P. O. Box 124, 22100 Lund, Sweden. \\ *mcmoranb@ub.edu
}

\begin{abstract}
The ability to entrap drugs within vehicles and subsequently release them has led to new treatments for a number of diseases. Based on an associative phase separation and interfacial diffusion approach, we developed a way to prepare DNA gel particles without adding any kind of cross-linker or organic solvent. Among the various agents studied, cationic surfactants offered particularly efficient control for encapsulation and DNA release from these DNA gel particles. The driving force for this strong association is the electrostatic interaction between the two components, as induced by the entropic increase due to the release of the respective counter-ions. However, little is known about the influence of the respective counter-ions on this surfactant-DNA interaction. Here we examined the effect of different counter-ions on the formation and properties of the DNA gel particles by mixing DNA (either single- (ssDNA) or double-stranded (dsDNA)) with the single chain surfactant dodecyltrimethylammonium (DTA). In particular, we used as counter-ions of this surfactant the hydrogen sulfate and trifluoromethane sulfonate anions and the two halides, chloride and bromide. Effects on the morphology of the particles obtained, the encapsulation of DNA and its release, as well as the haemocompatibility of these particles, are presented, using the counter-ion structure and the DNA conformation as controlling parameters. Analysis of the data indicates that the degree of counter-ion dissociation from the surfactant micelles and the polar/hydrophobic character of the counter-ion are important parameters in the final properties of the particles. The stronger interaction with amphiphiles for ssDNA than for dsDNA suggests the important role of hydrophobic interactions in DNA.
\end{abstract}




\section{Introduction}

A major research thrust in the pharmaceutical and chemical industries is the development of controlled release systems for drugs and bioactive agents. Many of these delivery systems in use and under development consist of a drug dispersed within a polymeric carrier. These chemicals provide the network structure and physical integrity, but they are usually toxic. In addition, problems encountered in reaching this goal are related not only to the preparation technology, but also to the intrinsic nature of the polymers. Indeed, encapsulation technologies imply the use of organic solvents and high-energy sources, thus leading to a significant degradation of the encapsulated molecule during the course of the polymer hydrolysis. ${ }^{1}$

A general understanding of the interactions between DNA and oppositely charged agents, and in particular phase behaviour, has provided a basis for developing novel DNA-based materials, including gels, membranes and gel particles. ${ }^{2}$ We recently prepared novel DNA gel particles based on associative phase separation and interfacial diffusion. By mixing solutions of DNA (either single-stranded (ssDNA) or double-stranded (dsDNA)) with solutions of different cationic agents, such as surfactants, proteins and polysaccharides, the possibility of the formation of DNA gel particles without adding any kind of cross-linker or organic solvent has been confirmed..$^{3-9}$ The strength of association, which is tuned by varying the structure of the cationic agent, allows control of the spatial homogeneity of the gelation process, producing either a homogeneous DNA matrix or different reservoir devices. This gives rise to various applications for the controlled encapsulation and release of SsDNA and dsDNA, with clear differences in their mechanism.

Of the several cationic agents studied, cationic surfactants offer particularly efficient control of the properties of these DNA-based particles. The formation of a physical network in which surfactant micelles form polyanionic-multicationic electrostatic complexes as cross-link points seems to play an important role in the stabilization of DNA particles. In addition, in the case of cationic surfactants with DNA, strong associative phase separation was observed. The driving force for this strong association is the electrostatic interaction between the two components, provided by the entropic increase due to the release of the respective counter-ions, which induces the binding of the surfactant to the polymer at low surfactant concentrations. The binding is cooperative due to the hydrophobic interactions between the surfactant molecules. Below the critical aggregation concentration (CAC) of the surfactant, no substantial binding takes place; above it, aggregates are formed between the polymer 
and the surfactant self-assemblies. The precipitation of the system may occur at the $\mathrm{CAC}$ or at higher concentrations, depending on the polyelectrolyte concentration and other properties of the system. ${ }^{10}$

The interactions of cationic surfactant with DNA have been studied extensively. Changes in the hydrophobic moiety of the surfactants affect their interaction with DNA. At a given concentration of surfactant, hexadecyltrimethylammonium bromide (HTAB) binds more readily to DNA, leading to the formation of a precipitate for smaller amounts of DNA than dodecyltrimethylammonium bromide (DTAB) does. ${ }^{10}$

The interactions of surfactants with DNA can also be tuned efficiently by controlling the head-group structure. The chemical structure of the head group markedly influences the interaction: negatively charged and non-ionic surfactants will not associate directly with DNA, for instance. It has also been observed that when structural modifications induced in the head group increase the hydrophobicity of the surfactant, ${ }^{11}$ such as the addition of an aromatic ring between the head group and the tail, the effect is similar to that of an increase in the surfactant chain length. Modifications of the head group can lead to other, more subtle, changes in the interactions between DNA and a surfactant, like the introduction of hydroxyl substituent into the head group. ${ }^{12}$

Little is known about the influence of the respective counter-ions on surfactant-DNA interaction. In general, oppositely charged macro-ions in solution attract each other, tending to form a bound complex. When separated, each macro-ion is surrounded by a diffuse layer of spatially confined counter-ions. Upon approach, the fixed macro-ion charges partially (sometimes fully) neutralize each other, allowing the release of mobile counter-ions into the bulk solution, thereby increasing their translational entropy. This scenario suggests that macro-ion association in solution is to a large extent an entropically driven process. ${ }^{13}$ The actual contribution of counter-ion entropy to free energy association depends on the detailed geometries and charge distributions of the separated and bound macro-ions. ${ }^{13-15}$

Understanding the interactions of the DNA-based particles with cells is crucial for improving their behaviour in vitro. We examined this interaction by using erythrocytes as a model biological membrane system, since erythrocytes have been used as a suitable model for studying the interaction of amphiphiles with biological membranes. 16-18 In addition, the potential uses of surfactant self-assemblies as drug delivery systems make haemolysis evaluation very important. 
Most in vitro studies of surfactant-induced haemolysis evaluate the percentage haemolysis by spectrophotometrically detecting plasma-free haemoglobin derivatives after incubating surfactant solutions with blood and then separating undamaged cells by centrifugation. However, in the case of particles, interpreting the results of these studies is complicated due to the variability of experimental approaches and a lack of universally accepted criteria for determining test-result validity.

In this context, the purpose of the present study was to investigate the effect of different counter-ions on the formation and properties of DNA gel particles, by mixing DNA (either single-stranded (ssDNA) or double-stranded (dsDNA)) with the singlechain surfactant surfactant, dodecyltrimethylammonium (DTA). In particular, we employed, as counter-ions of this surfactant, anions of the two extremes in the Hofmeister series (hydrogen sulfate and trifluoromethane sulfonate) and two halides (chloride and bromide). The effects on morphology of the particles obtained, the encapsulation of DNA and its release and the haemocompatibility of these particles are presented, using the counter-ion structure and DNA conformation as controlling parameters.

\section{MATERIALS AND METHODS}

\section{Materials}

The sodium salt of deoxyribonucleic acid (DNA) from salmon testes with an average degree of polymerization of about 2,000 base pairs was purchased from Sigma and used as received. DNA concentrations were determined spectrophotometrically, on the basis that for an absorbance of 1, at $260 \mathrm{~nm}$, a solution of dsDNA has a concentration of $50 \mu \mathrm{g} / \mathrm{mL}$. ${ }^{19}$ All DNA concentrations are given in molarity per phosphate group, i.e. molarity per negative charge. The ratios in absorbance at 260 and $280 \mathrm{~nm}$ of the stock solutions were found to be between 1.8 and 1.9, which suggested the absence of proteins. $^{20} \quad$ Dodecyltrimethylammonium chloride (DTAC) and dodecyltrimethylammonium bromide (DTAB) were purchased from Fluka and dodecyltrimethylammonium hydrogen sulphate (DTAHs) was from Aldrich. All three were used as received. Dodecyltrimethylammonium trifluoromethane sulphonate (DTATf) was prepared in our lab. ${ }^{21}$ In short, starting from the DTAC derivative, triflate substitution was achieved by using a Dowex $21 \mathrm{~K}$ exchange resin equilibrated with $\mathrm{NaOH}$. The resin loaded with DTAC was then gravity-eluted though the column. Thus, the DTAOH derivative was obtained and titration was immediately performed with triflic acid, until $\mathrm{pH}$ reached the value of 6 . The solution containing the DTATf derivative was 
dried and the powder was recrystallized in methanol/ether (10:90). The melting point of the powder $\left(168^{\circ} \mathrm{C}\right)$ was used to ascertain its purity. The Krafft temperature for the DTATf system was determined through conductance measurements at $37^{\circ} \mathrm{C}$.

$\mathrm{N}, \mathrm{N}, \mathrm{N}^{\prime}, \mathrm{N}$ '-tetramethylacridine-3,6-diamine (acridine orange $(\mathrm{AO})$ ) was supplied by Molecular Probes (Invitrogen). 9-(diethylamino)benzo[a]phenoxazin-5(5H)-one (Nile red, NR) was supplied by Fluka. All experiments employed Millipore Milli-Q de-ionized water (18.2 $\mathrm{M} \Omega \mathrm{cm}$ resistivity).

\section{Particle preparation}

The dsDNA stock solutions were prepared in $\mathrm{NaBr} 10 \mathrm{mM}$ in order to stabilize the DNA secondary structure in its native B-form conformation. ssDNA stock solutions were prepared by thermal denaturation of dsDNA stock solutions at $80^{\circ} \mathrm{C}$ for 15 min and then immediate dipping into ice for fast cooling to prevent renaturation. Surfactants were dissolved in Millipore Milli-Q de-ionized water and equilibrated at $25^{\circ} \mathrm{C}$ or $45^{\circ} \mathrm{C}$, in order to reach the Krafft temperature of the entire surfactant. DNA solutions were added dropwise via a 22-gauge needle into gently agitated surfactant solutions (2 ml). Under optimal conditions, droplets from DNA solutions instantaneously gelled into discrete particles on contact with the surfactant solution. Thereafter, the particles were equilibrated in the solutions for a period of 2 hours. After this period the particles formed were separated by filtration through a G2 filter and washed with $5 \times 8 \mathrm{ml}$ volumes of Milli-Q water to remove the excess of salt.

\section{Determination of degree of DNA entrapment}

The degree of entrapment was determined by quantifying both the non-bound DNA in the supernatant solution and the bound DNA in the gel particles. The entire quantity of supernatant surfactant solution containing the non-bound DNA was removed for quantification by spectrophotometry. Thereafter, the particles were washed with Milli- $Q$ water, as described in the previous section. The particles were magnetically stirred in $\mathrm{pH} 7.610 \mathrm{mM}$ Tris $\mathrm{HCl}$ buffer to promote swelling and break-up of the structure. The resulting mixture, containing skins of the particles, was filtered; then the filtrates were quantified by a spectrophotometer. The amount of DNA present in the skins obtained was calculated from the initial amount of DNA added. Loading capacity $(L C)$ and loading efficiency $(L E)$ were determined by the following equations: 
$L C(\%)=[($ total amount of DNA- non-bound DNA)/weight of particles $] \times 100$

$L E(\%)=[($ total amount of DNA- non-bound DNA $) /$ total amount of DNA $] \times 100$

Three batches of particles of each system were prepared and results are given as average and standard deviations.

\section{Fluorescence microscopy imaging}

Particle integrity and the DNA conformational state were determined by the acridine orange (AO) fluorescent assay. Thus, freshly prepared particles were stained for 10 min with $A O(0.3 \mathrm{mg} / \mathrm{ml})$ and washed in distilled water.

In addition, changes in local polarity of the particles obtained were determined by the Nile red (NR) staining assay. Thus, a stock solution of $\mathrm{NR}(0.5 \mathrm{mg} / \mathrm{ml}$ in acetone) was prepared. A working solution was prepared by adding $0.05 \mathrm{ml}$ of stock solution to $50 \mathrm{ml}$ of a 75:25 glycerol-water mixture. A drop of working solution was added to the particles.

The stained samples were immediately examined with an Olympus BX51M microscope equipped with a UV-mercury lamp (100W Ushio Olympus) and a MNIBA3-type filter set (470-495 nm excitation and $505 \mathrm{~nm}$ dichromatic mirror). Images were digitized on a computer through a video camera (Olympus digital camera DP70) and were analyzed with an image processor (Olympus DP Controller 2.1.1.176, Olympus DP Manager 2.1.1.158). All observations were carried out at $25^{\circ} \mathrm{C}$.

\section{Swelling and dissolution behaviour of the particles}

Studies were conducted in pH 7.6 $10 \mathrm{mM}$ Tris $\mathrm{HCl}$ buffer. Particles (around $100 \mathrm{mg}$ ) were exposed to dissolution media at an agitation rate of $40 \mathrm{rpm}$ and at room temperature, using the ST 5 CAT shaking platform. At specific time intervals, the entire quantity of dissolution medium was removed and particles remaining in the container were weighed. Then, fresh solution was added in order to maintain a clean environment. This procedure was repeated until the particles were completely dissolved. The data were then transformed to relative weight loss by the following equation:

Relative weight ratio $(R W)=W_{t} / W_{i}$ 
Where $W_{i}$ stands for the initial weight of the particles and $W_{t}$ for the weight of the particles at time $t$.

\section{DNA release from the particles}

Simultaneously to the studies of swelling/dissolution behaviour, DNA release studies were carried out. Hence, at defined time intervals, the supernatant was collected and particles were re-suspended in fresh solution. DNA released into the supernatant solutions was quantified by measuring the absorbance at $260 \mathrm{~nm}$ with a spectrophotometer (UV/VIS UV-2450 Spectrophotometer, Shimadzu).

\section{Interaction with erythrocytes}

Blood was obtained from anaesthetized rats by cardiac puncture and drawn into tubes containing EDTA. The procedure was approved by the institution's Ethics Committee on Animal Experiments. The serum was removed from the blood by centrifugation at 3,000 rpm (Megafuge 2.0 R Heraeus Instruments) at $4^{\circ} \mathrm{C}$ for $10 \mathrm{~min}$ and by subsequent suction. The red blood cells were then washed three times at $4^{\circ} \mathrm{C}$ by centrifugation at 3,000 rpm with isotonic saline PBS solution, containing $22.2 \mathrm{mmol} / \mathrm{L} \mathrm{Na} \mathrm{HPO}_{4}, 5.6$ $\mathrm{mmol} / \mathrm{L} \mathrm{KH}_{2} \mathrm{PO}_{4}$ and $123.3 \mathrm{mmol} / \mathrm{L} \mathrm{NaCl}$ in distilled water $(\mathrm{pH} 7.4)$. Following the last wash, the cells were diluted to $1 / 2$ their volume with isotonic PBS solution (cell density of $\left.8 \times 10^{9} \mathrm{cell} / \mathrm{mL}\right)$.

For the haemolytic study, haemolysis assay experiments were performed. First, the haemolytic response of the different surfactants in solution was tested. Thus, a series of different volumes of surfactant solution (10 mg/mL), ranging from 10 to $80 \mu \mathrm{L}$, were placed in polystyrene tubes and an aliquot of $25 \mu \mathrm{L}$ of erythrocyte suspension was added to each tube. The final volume was $1 \mathrm{~mL}$. The tubes were incubated at room temperature for 10 min under shaking conditions. Following incubation, the tubes were centrifuged ( $5 \mathrm{~min}$ at $10,000 \mathrm{rpm}$ ). The degree of haemolysis was determined by comparing the absorbance $(540 \mathrm{~nm}$ ) (Shimadzu UV-160A) of the supernatant with that of the control samples totally haemolysed with distilled water. Positive and negative controls were obtained by adding an aliquot of $25 \mu \mathrm{L}$ of erythrocyte suspension to bidistilled water and isotonic PBS solution, respectively.

In the case of DNA particles, individual DNA gel particles were placed in the tubes and an aliquot of $25 \mu \mathrm{L}$ erythrocyte suspension was added to each tube. The final volume 
was $1 \mathrm{~mL}$. The tubes were incubated at room temperature for different times under shaking conditions. At defined times, the incubated samples were centrifuged ( $5 \mathrm{~min}$ at $10,000 \mathrm{rpm})$. The degree of haemolysis was determined as described above.

At the same time as the haemolysis assay experiments with the DNA particles, the DNA release from the DNA gel particles was determined. For this, individual DNA gel particles were placed in the tubes and isotonic PBS solution was added till reaching a final volume of $1 \mathrm{~mL}$. The tubes were incubated at room temperature for the same defined times as in the haemolysis assay experiments, under shaking conditions. Following incubation, the tubes were centrifuged (5 min at $10,000 \mathrm{rpm}$ ). The concentration of dsDNA or ssDNA released on the supernatants was determined by using the NanoPhotometer ${ }^{\mathrm{TM}}$ (Implen.)

The correlation between the erythrocyte population and the haemolytic response in the presence of the particles was established by counting the number of erythrocytes at defined times, using a Bürker-Türk counting chamber coupled to a microscope.

\section{RESULTS}

\section{Particle preparation}

Particles were prepared at a charge ratio between DNA and cationic agent equal to 1 , $R=[\mathrm{DNA}] /\left[\mathrm{S}^{+}\right]$, where $\left[\mathrm{S}^{+}\right]$is the concentration of the corresponding surfactant (concentrations determined per charge). In all cases, the DNA concentration was set to $60 \mathrm{mM}$. This DNA concentration was chosen because it produces high-viscosity solutions, which makes it an appropriate system for the preparation of stable DNA gel particles. $^{3-9}$

Particles were prepared by dropwise addition of DNA solutions to the surfactant solutions, equilibrated at 25 or $45^{\circ} \mathrm{C}$. Because of the relatively high viscosity of the DNA solution, mixing of the two solutions is not instantaneous. Therefore, before the two solutions can mix, the surfactant diffuses into the polyelectrolyte phase and forms a gel shell at the interface, stabilizing the particles. This is the general behaviour observed for DNA placed in DTAB, DTAC and DTATf solutions. However, in the case of DTAHs, DNA drops disrupted quickly on contact with the DTAHs solution, and the formation of the corresponding DNA gel particles did not take place. Similar behaviour was observed in the case of particles prepared with denatured DNA. Changes in the 
$\mathrm{pH}$ values of the corresponding surfactant solutions could explain the performance observed. Whereas the $\mathrm{pH}$ of the solutions containing DTAB, DTAC and DTATf is in the 5.9 to 6.5 range, very low $\mathrm{pH}(\approx 1.8)$ was determined in the case of DTAHs. In this case, acidic conditions may play a role in the protonation of the DNA bases, ${ }^{22}$ contributing negatively to the opposite polymer-surfactant interaction.

\section{Determination of the degree of DNA entrapment}

The degree of DNA entrapment is expressed through the loading efficiency and loading capacity values. Loading efficiency $(L E)$ is calculated by comparing the amount of DNA included in the particles with the total amount during particle formation. Loading capacity $(L C)$ takes the amount of DNA entrapped in the particles as a function of their weight. The loading efficiency $(L E)$ and the loading capacity $(L C)$ for the different formulations depend on the surfactant used. The characteristics of the different systems are summarized in Figure 1. 

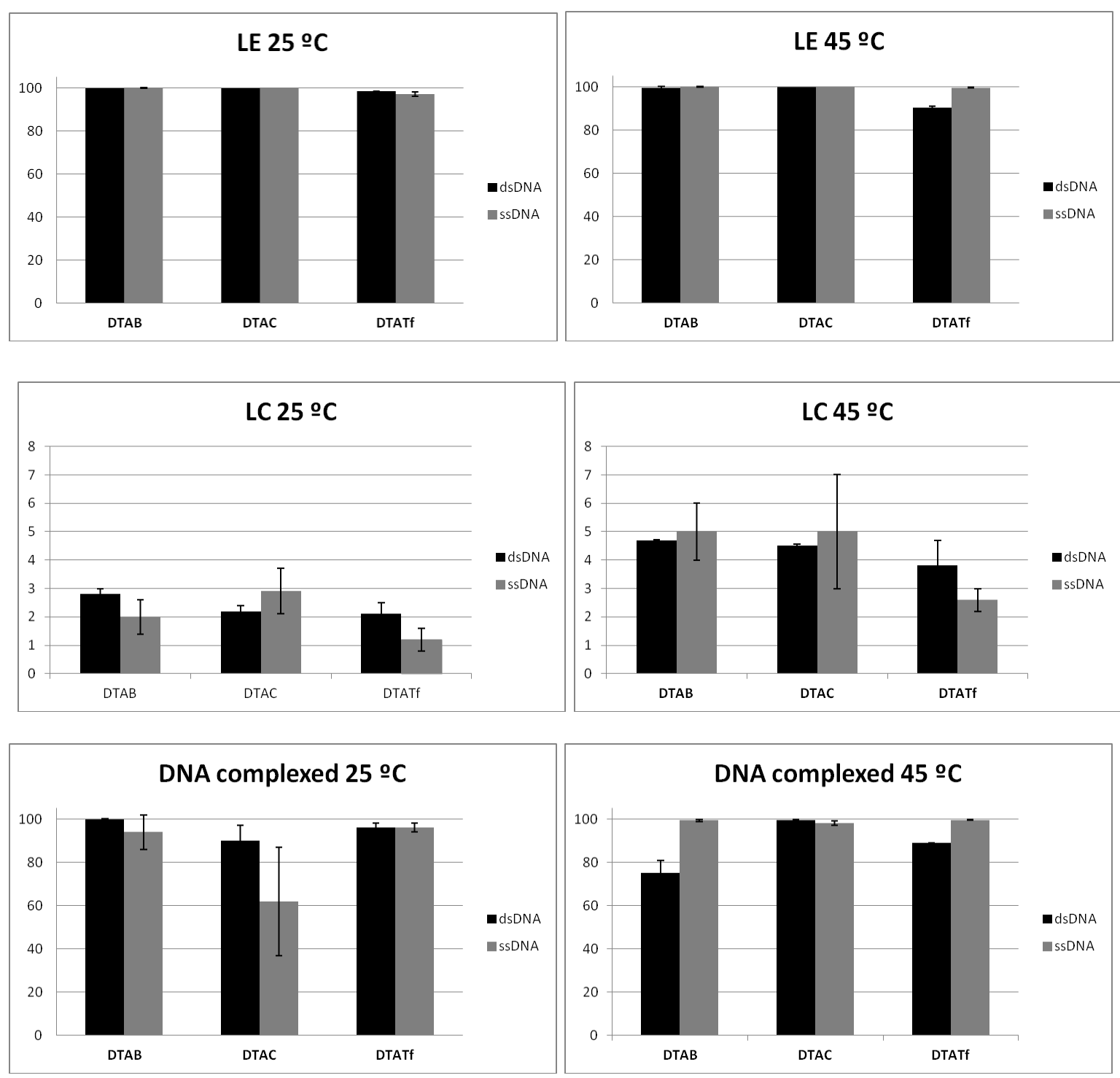

Figure 1. Characterization of the DNA gel particles with respect to DNA loading efficiency $(L E)$, loading capacity $(L C)$ and DNA complexed as a function of the surfactant counter-ion, temperature and secondary structure of the DNA. Complexed DNA is related to the amounts of DNA in the supernatant solutions and the skins derived from the particles, after particles were magnetically stirred overnight. All values were measured in triplicate and are given as average and standard deviation.

Using DTAC and DTAB, the $L E$ values found were higher than $99 \%$ for the two temperatures studied. In the case of DTATf, experiments carried out at $25^{\circ} \mathrm{C}$ showed $L E$ values ranging between $97-98 \%$. However, increasing the temperature to $45^{\circ} \mathrm{C}$ raises $L E$ for the DTATf-ssDNA systems (> 99\%).

The determination of the entrapped DNA as a function of the weight of the particles showed $L C$ values ranging from $1.2-2.9 \%$ for experiments carried out at $25^{\circ} \mathrm{C}$. The lowest $L C$ values were obtained for the DTATf-ssDNA system. Surfactants containing 
chloride or bromide as the corresponding counter-ions produce similar $L C$ values. When particle formation takes place at $45^{\circ} C, L C$ values are double those obtained at the lower temperature.

An indication of the structural characteristics of these DNA particles can be gleaned from the amount of DNA that was released when the break-up of the particles was induced mechanically. The percentages of DNA complexed are summarized in Figure 1. These values suggest that, by using these three surfactants, most of the DNA is complexed during the particle formation. The formation of these fully collapsed particles is consistent with the formation when using other surfactants with an identical hydrophobic contribution. ${ }^{6}$

\section{Morphological characterization of the DNA gel particles}

Fluorescence microscopy using the fluorescence dye, acridine orange $(A O)$, was used to confirm the presence of DNA and to assess the secondary structure of the nucleic acid in the particles. AO (excitation: $500 \mathrm{~nm} /$ emission: $526 \mathrm{~nm}$ ) intercalates into double-stranded DNA as a monomer, whereas it binds to single-stranded DNA as an aggregate. On excitation, the monomeric acridine orange bound to double-stranded DNA fluoresces green, with an emission maximum at $530 \mathrm{~nm}$. The aggregated acridine orange on single-stranded DNA fluoresces red, with an emission at about $640 \mathrm{~nm}$. ${ }^{23,24}$

Figure 2 shows fluorescence micrographs of individual particles. FM images of freshly prepared particles using $A O$ as staining (left panels) showed green emission, independently of the initial secondary structure of the DNA. The absence of red emission in the particles containing denatured DNA suggests that the accessibility of free DNA to the dye is hindered. The morphologies seen are consistent with the data on DNA distribution described above (Figure 1).

Similar studies were carried out using Nile red (NR) as staining. This test showed solvatochromic behaviour. In polar media a red shift in the emission maximum was observed, together with fluorescence quenching, due to the capacity of NR to establish hydrogen bonds with protic solvents. ${ }^{25}$ In consequence, the NR emission in water was very weak, with an emission maximum at $660 \mathrm{~nm} .^{26}$

In the case of particles formed with DTATf, emission intensity increases (Figure 2, right panels), indicating that NR becomes less exposed to water in this system. The difference in emission in Figure 2 provides strong evidence that the triflate ions of 
DTATf-DNA complexes provide a hydrophobic "environment" for NR, but not in the case of the two halide ions studied.

Some features about water distribution in these systems can be deduced from the FM studies, using NR for staining (Figure 2). Particles formed with surfactants containing the two halogens as counter-ions showed almost no emission of the dye. However, particles formed with the surfactant DTATf revealed an increase in its emission. These results suggest that, in the latter case, the dye NR remains less exposed to water in this system. It has been found that the dye NR is very sensitive to local polarity (dielectric constant of the microenvironment) and can be used as a probe for hydrophobic surfaces in proteins. In a polar environment NR has a low fluorescence quantum yield, whereas in more hydrophobic environments its quantum yield increases and its emission maximum becomes progressively blue-shifted. This property has been used for probing non-polar sites in biomolecules (proteins and lipids). ${ }^{27}$ 


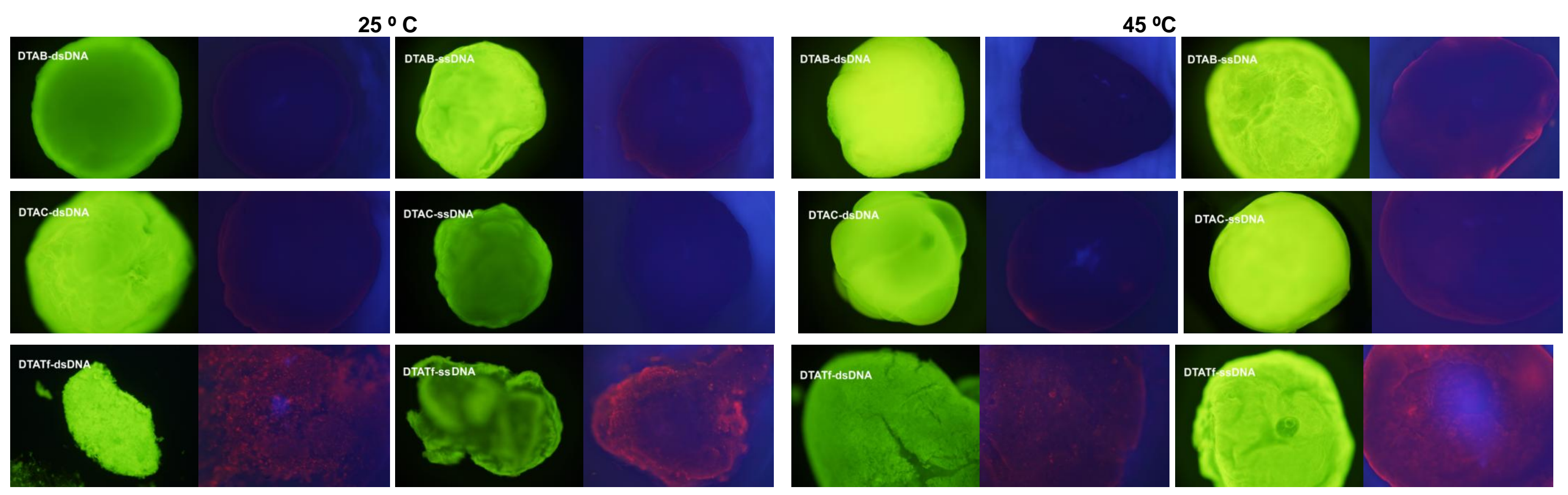

Figure 2. Fluorescence micrographs of the different DNA gel particles in the presence of the fluorescent dyes, AO (left, green emission) and NR (right, red emission), at $25^{\circ} \mathrm{C}$ and $45^{\circ} \mathrm{C}$. 


\section{Swelling kinetics}

Gels are thought to have great potential as drug reservoirs. Loaded drugs are released by diffusion from the gels or by erosion. Hence, the release mechanism can be controlled by swelling or dissolution of the gels. Figure 3 shows the relative weight ratio of the different gel particles after exposure to a Tris. $\mathrm{HCl}$ pH 7.4 buffer solution.

Swelling experiments carried out with the different DTA-DNA particles demonstrated that the relative weight depends on both the counter-ion on the surfactant structure and on the secondary structure of the nucleic acid. Although the degree of swelling seems to be higher when particles are prepared at $45^{\circ} \mathrm{C}$ for both temperatures, the degree of swelling for DTAssDNA systems (relative weight ratio, RW 3-13, using the maximum points as estimate) is higher than that using native DNA (RW: 3-5). In addition, in the case of particles prepared with denatured DNA, it was found that the degree of swelling increased in the sequence DTATf $<$ DTAB $<$ DTAC.
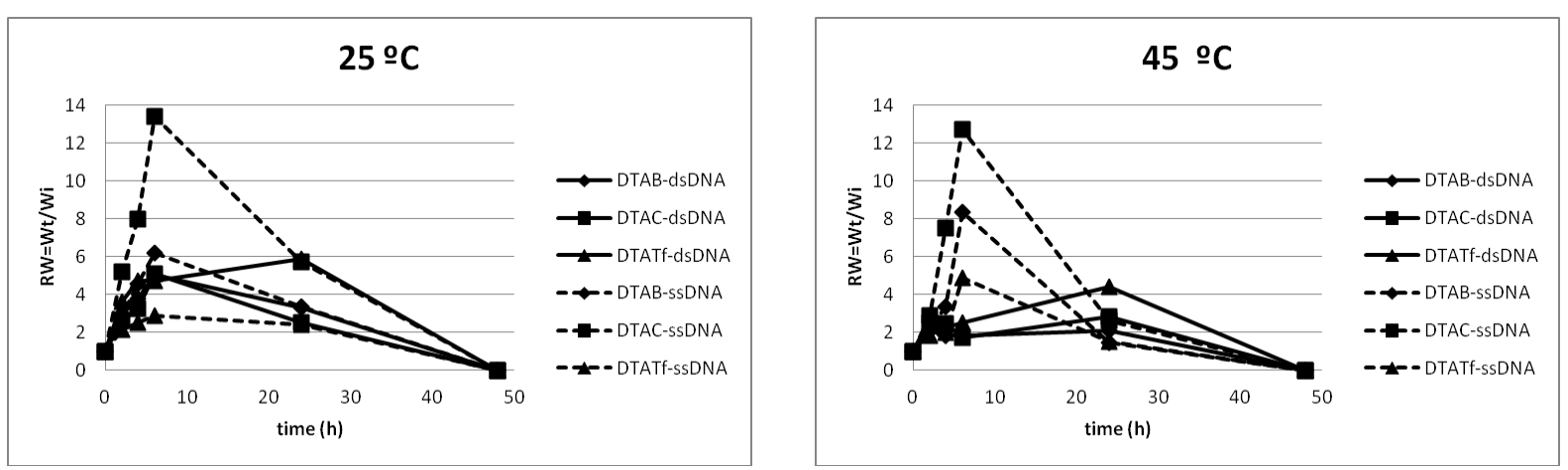

Figure 3. Time-dependent changes of the relative weight of DNA gel particles studied.

\section{DNA release}

Generally, the release pattern resembles that observed in the swelling/dissolution profiles (see Figure 3). Thus, particles prepared using the native nucleic acid had a faster release in the sequence DTATf > DTAB > DTAC as a consequence of the dissolution profile. In the case of particles formed with denatured DNA, slower kinetics were observed, which is congruent with that observed for the swelling/dissolution profiles. 

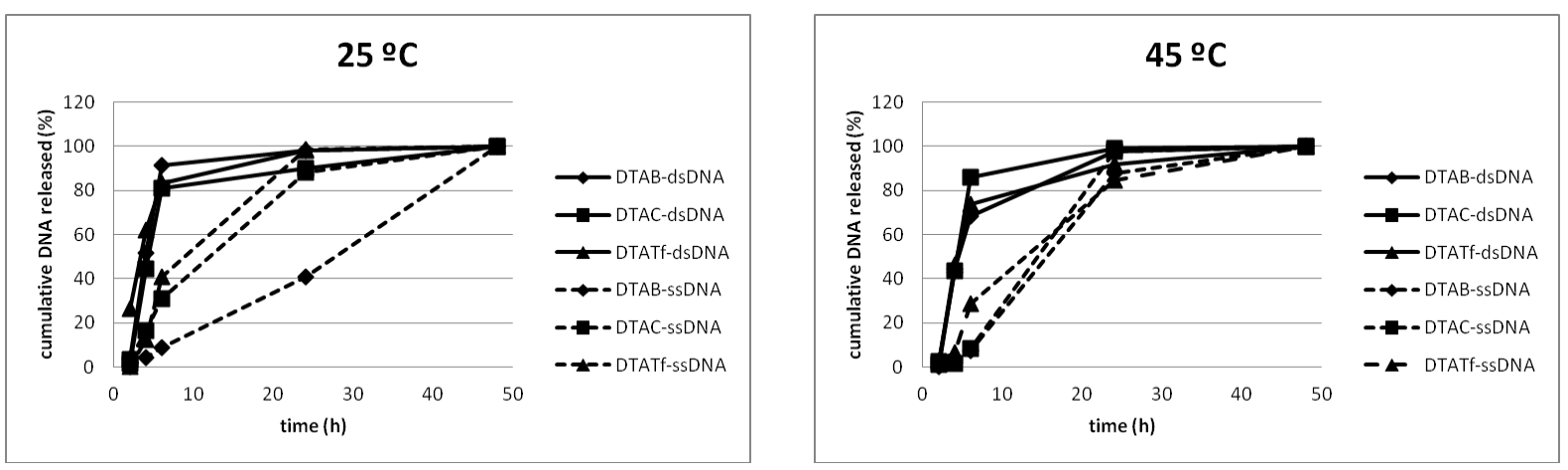

Figure 4. Time-dependent changes in DNA release profiles for the DNA gel particles studied.

\section{Haemolytic assessments}

Haemolysis by surfactants is a process of great fundamental and practical importance. Erythrocytes lack internal organelles and, since they are the simplest cellular model obtainable, they are the cell membrane systems most commonly used for study of the surfactant-membrane interaction. In addition, the potential uses of surfactant self-assemblies as drug delivery systems make the evaluation of haemolysis very important.

The haemolytic potency of the different components was determined separately. The dependence of haemolysis on the concentration of the surfactant structure is shown in Figure 5. In this experiment, haemolysis was determined at a fixed time, after 10 min incubation in the presence of various surfactant concentrations. Haemolysis varied with the surfactant concentration in a sigmoidal manner. At concentrations below $300 \mathrm{ug} / \mathrm{mL}$, for DTAB and DTATf surfactants, the percentage of haemolysis was not significant (below $<5 \%$ ), which can be regarded as a non-toxic effect level. However, it increased sharply between 400 and 600 (or $700 \mathrm{ug} / \mathrm{mL}$, depending on the surfactant structure) to reach essentially $100 \%$ haemolysis at that concentration. The concentrations assayed were well below 4,000-4,500 $\mathrm{ug} / \mathrm{mL}$, which corresponds to the CMC (Critical Micelle Concentration) value of the surfactants, as previously determined (5. 0 mM DTATf, ${ }^{21} 15.0 \mathrm{mM} \mathrm{DTAB}^{28}{ }^{20} 20.0 \mathrm{mM} \mathrm{DTAC}^{29}$ ). The sigmoidal pattern of this DTA-induced haemolysis (Figure 5) is indicative of a complex process in which sufficient surfactant needs to accumulate in the target membrane to induce the osmotic lysis of erythrocytes.

The $\mathrm{HC}_{50}$ values for the different surfactant structures are 443,468 and $510 \mu \mathrm{g} / \mathrm{mL}$ for DTAC, DTATf and DTAB, respectively. The haemolytic potency of the DNA was also determined. As expected, DNA showed no haemolytic activity (results not shown). 


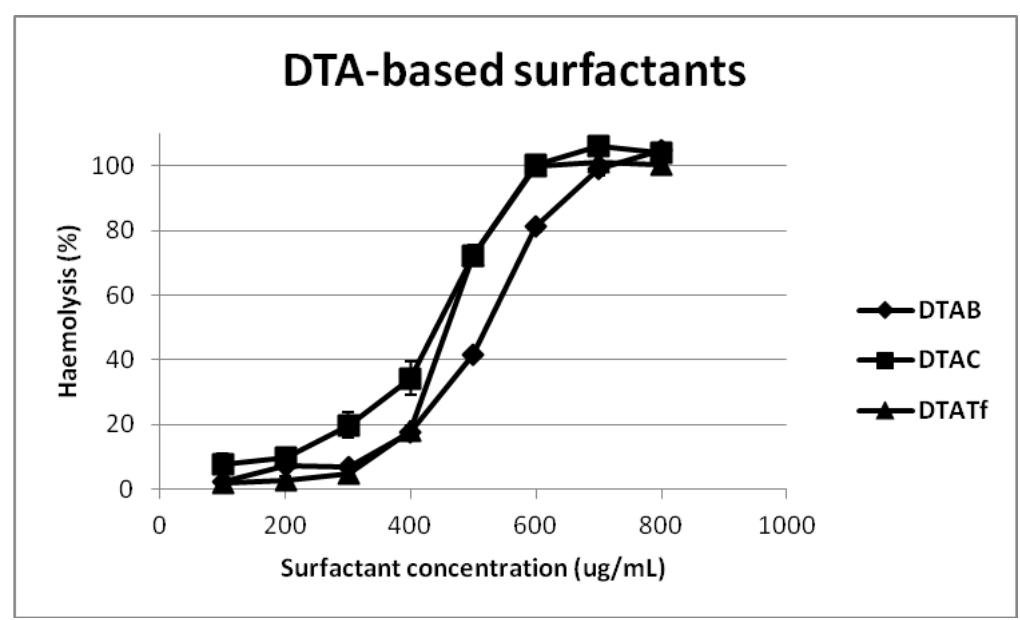

Figure 5. Dependence of rat erythrocyte haemolysis on DTA-based surfactant concentration. Erythrocytes were incubated for $10 \mathrm{~min}$ at room temperature at different surfactant concentrations, and the amount of haemoglobin released was determined. The data correspond to the average of three independent experiments \pm standard deviation.

Although the $\mathrm{HC}_{50}$ values for these three surfactants are very close (see Figure 5), strong differences were found when the kinetics of haemolysis of the corresponding surfactantdsDNA particles were determined. Figure 6 shows the surfactant-induced haemolysis of rat erythrocytes from surfactant-DNA gel particles as a function of time. In the case of surfactant-dsDNA particles, haemolysis is a relatively slow process, including the presence of an initial lag period in all curves. This lag period varies between $30 \mathrm{~min}$ in the case of systems containing DTAB and 90 min for the systems containing the surfactants DTAC and DTATf. Both the maximum percentage of haemolysis and the corresponding time are dependent on the surfactant structure. After $120 \mathrm{~min}, 75$ and $85 \%$ haemolysis was achieved for the systems containing DTAB and DTAC as surfactants, respectively. The subsequent decrease from the maximum haemolysis values for longer incubation times (150 and $180 \mathrm{~min}$ ) may correlate with differences in particle size. There was a more limited haemolytic effect when particles were prepared with DTATf. At the end of the experiment (180 min), only $70 \%$ haemolysis had been achieved. 

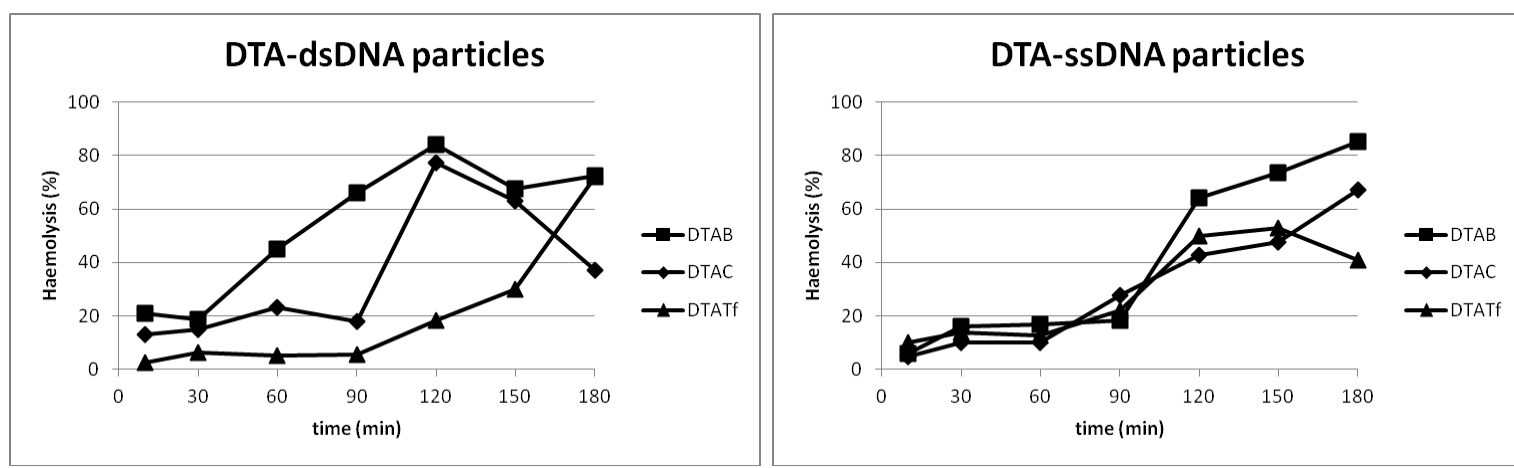

Figure 6. DTA-DNA particle-induced haemoglobin release from rat erythrocytes as a function of time. Erythrocytes were incubated at room temperature in the presence of individual DTADNA particles.

Similar experiments were carried out with particles prepared with denatured DNA. In this case, the initial lag extended to $90 \mathrm{~min}$ for all three surfactant-ssDNA systems. The maximum haemolysis values are 53,65 and $85 \%$ for the systems containing DTATf, DTAC and DTAB as surfactants, respectively.

Since the haemolytic character of these surfactants in solution is almost identical, the differences found in the kinetics of the haemolysis responses induced by the different surfactants are related to their capacity to form weaker or stronger surfactant-DNA complexes. It is expected that, for a higher degree of complexation, a smaller amount of surfactant would be released in solution, an amount able to interact with the erythrocyte membrane and promote haemoglobin release into the media.

\section{Relationship between the degree of haemolysis and the number of erythrocytes}

Determination of haemolytic properties is one of the most common tests in studies of particle interaction with blood components. Interpreting the results of these studies is complicated due to variability in experimental approaches and a lack of universally accepted criteria for determining the test-result validity. Most in vitro studies of particle-induced haemolysis evaluate the percentage of haemolysis by spectrophotometrically detecting plasma-free haemoglobin derivatives after incubating the particles with blood and then separating undamaged cells by centrifugation. However, some particle interference due to haemoglobin precipitates adsorbed with the particles on centrifugation has been reported, yielding a false negative result. ${ }^{30}$ 
To avoid these false negative results in the haemolytic response of these surfactant-DNA particles, the evolution of both haemolytic activity and the number of erythrocytes in the dispersions for each time were determined simultaneously. Figure 7 shows the results. There is a good relationship between the degree of haemolysis found and the number of erythrocytes. In all cases, low values of haemolytic responses correspond to a high number of erythrocytes in the corresponding dispersion; and an increase in haemolysis corresponds to a decrease in the number of erythrocytes. Thus, the effect of adsorbed haemoglobin on the particles can be considered negligible.
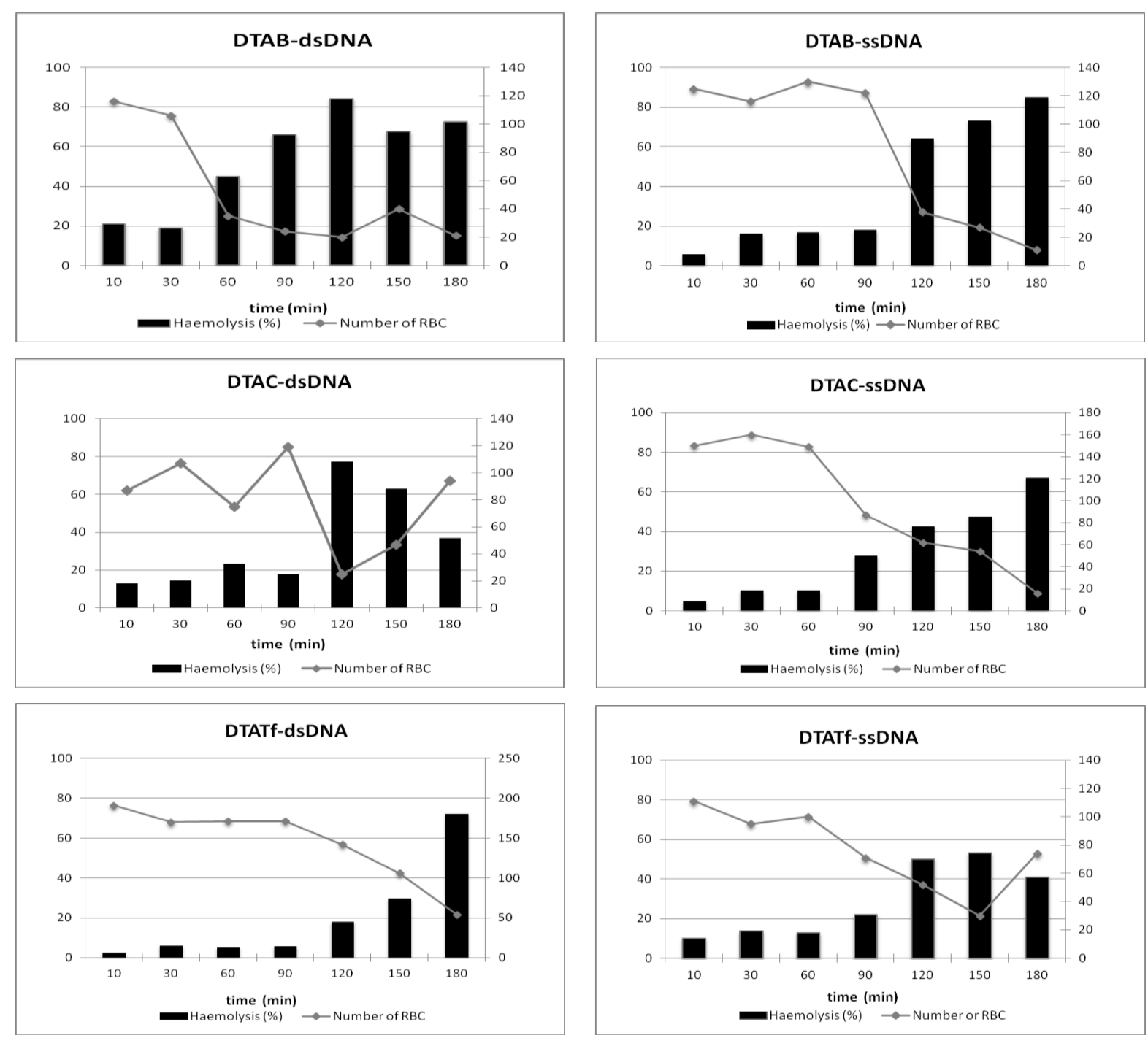

Figure 7. Time-course of the haemolytic response and the number of erythrocytes in the dispersions. 


\section{Relationship between the DNA released and the degree of haemolysis}

Previous studies have demonstrated the possible use of these DNA gel particles in the controlled encapsulation and release of dsDNA and ssDNA (see Figure 4). However, in this study, the main interest was to characterize these DNA gel particles by considering simultaneously their kinetics of DNA release and their haemolytic response. Thus, DNA released from the different DTA-DNA particles was continuously monitored in a separate assay under the same conditions described above for haemolysis. Figure 8 shows the relative kinetics of DNA and haemoglobin release. In all cases, there was close correlation between the haemolytic activity found and the amount of DNA released. Both parameters increased with time. Although the haemolytic response was not directly associated with the DNA released, which showed no haemolytic activity, both parameters were a consequence of the dissociation of the surfactant-DNA complex.

The amount of DNA that is released and the haemolytic response are strongly dependent on both the structure of the counter-ion in the surfactant and the secondary structure of the DNA. In the case of particles prepared with native DNA, the amount of dsDNA that is released at the end of the experiment (180 $\mathrm{min}$ ) reaches $100 \mu \mathrm{g} / \mathrm{mL}$. However, with particles prepared with denatured DNA, only $10 \%$ of this amount is released into the media. This behaviour, which can be correlated with the degree of complexation, is higher in the case of ssDNA, thus decreasing the amount of non-complexed DNA that could be detected in solution. These differences are also supported by visual inspection: surfactant-dsDNA particles are completely dissolved at the end of the experiment, whereas surfactant-ssDNA particles are still present after $180 \mathrm{~min}$.

At this point, it is possible to establish which of these systems is the most haemocompatible. For this, the haemolysis values for a defined amount of released DNA are compared. In the case of the surfactant-dsDNA particles, for a concentration of dsDNA equal to $100 \mu \mathrm{g} / \mathrm{mL}$, the degree of haemolysis is $30 \%, 60 \%$ and $80 \%$, when DTATf, DTAC and DTAB are used as cationic agents, respectively. In the case of surfactant-ssDNA particles, and for a concentration of ssDNA equal to $5 \mu \mathrm{g} / \mathrm{mL}$, the degree of haemolysis is $20 \%, 50 \%$ and $70 \%$, when DTATf, DTAC and DTAB are used as surfactants, respectively. It is interesting to note that the haemolytic response follows the sequence DTATf $<D T A C<D T A B$, independently of the secondary structure of the DNA. 

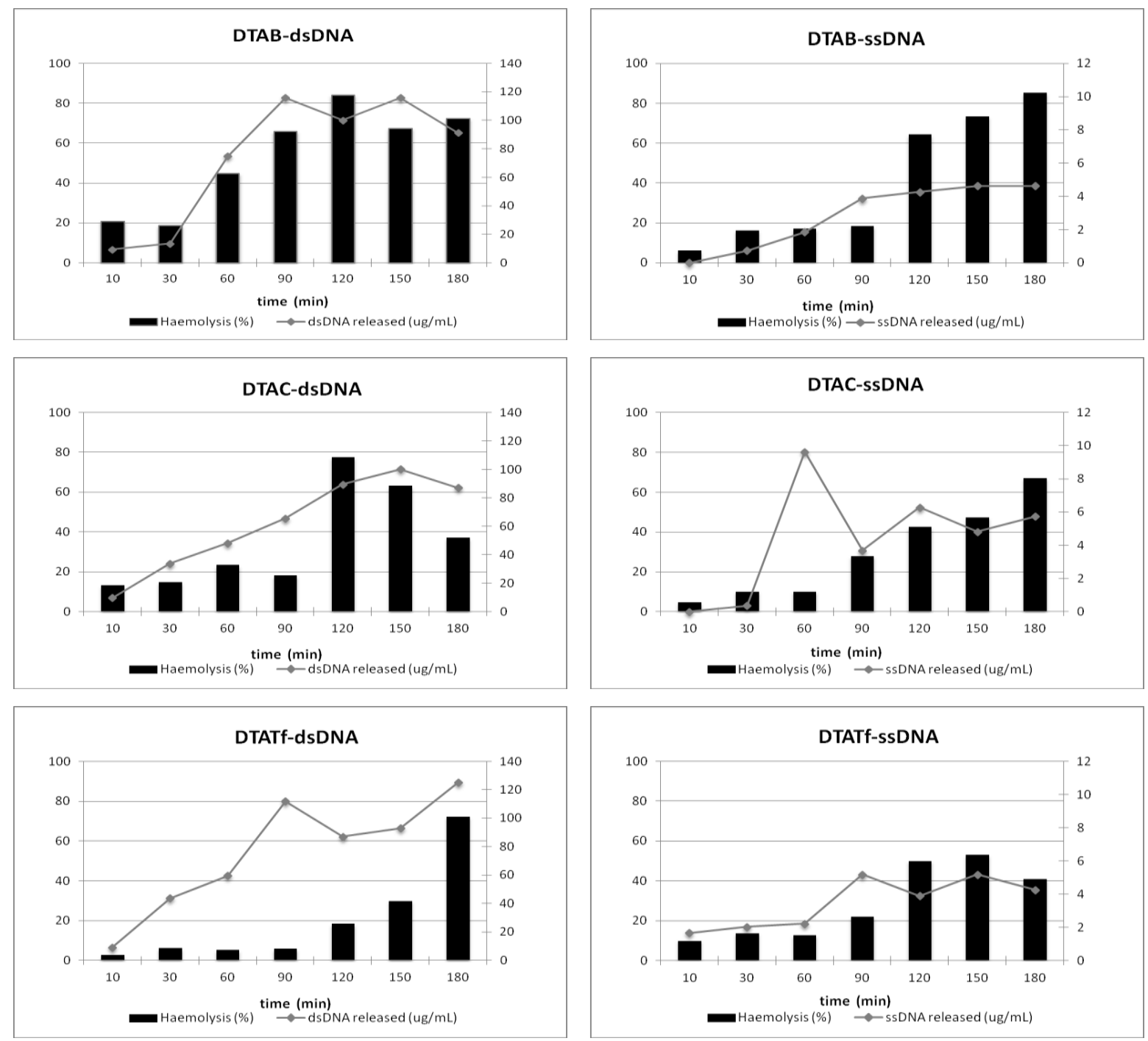

Figure 8. Relative kinetics of DTA-DNA particle-induced haemoglobin release from rat erythrocytes and DNA release.

\section{Calculation of the surfactant content and complexation stoichiometry}

The fitting of the haemolysis activity profiles of both the surfactants in solution and those of the corresponding surfactant-DNA particles enabled us to calculate the surfactant release from the particles as a function of time. The surfactant concentration in the different systems is shown in Figure 9. 

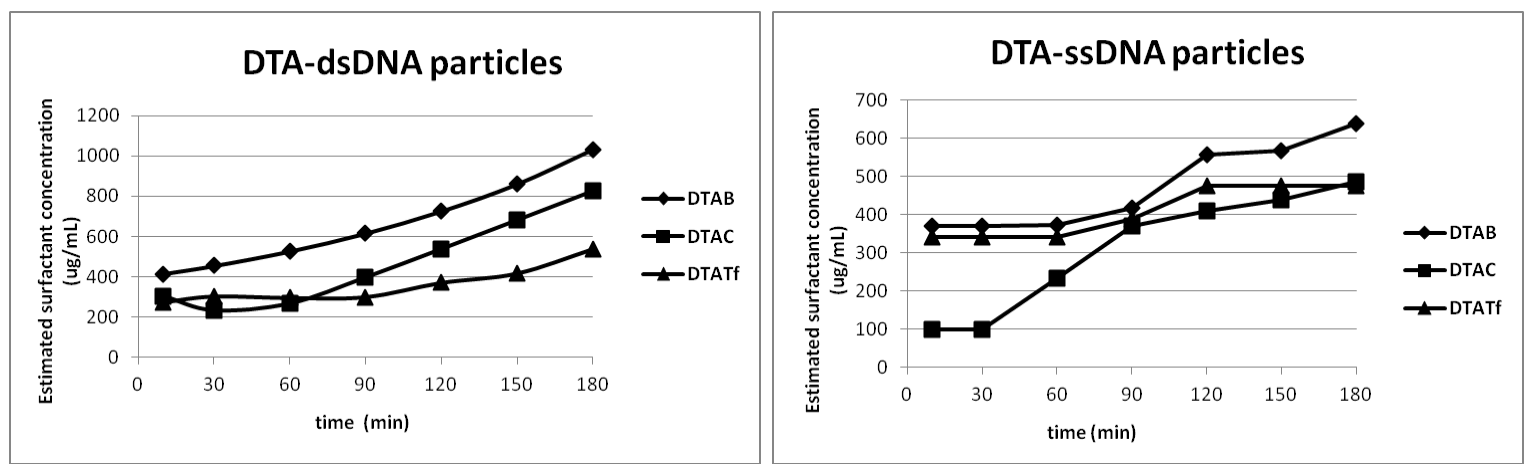

Figure 9. Surfactant released from DTA-DNA particles as a function of time.

The evolution of the surfactant release is strongly dependent on both the counter-ions present in the surfactant structure and the secondary structure of the DNA. In the case of DTA-dsDNA particles, the surfactant released increased continuously over time as a consequence of particle dissolution. As noted above, at the end of the experiment, the particles dissolved totally. The surfactant concentration at this point provided us with information about the total concentration of surfactant in the particles. It is worth noting that a simple modification of the surfactant structure, i.e. the corresponding counter-ion, can strongly modulate surfactant concentration in the particles. The concentration of surfactant included on the DTA-dsDNA particles ranges from $500 \mu \mathrm{g} / \mathrm{mL}$, in the case of DTATf-dsDNA particles, to $1,000 \mu \mathrm{g} / \mathrm{mL}$ in the case of DTAB-dsDNA particles.

When denatured DNA is used in the formation of the DTA-DNA particles, the evolution of the surfactant release is less dependent on time. The surfactant concentrations remained constant over time or showed small changes in their profiles. At the end of the experiment, as particles remained still visible on the dispersions, the total amount of the surfactant included in the particles could not be estimated. The concentration of surfactant released into the media after $180 \mathrm{~min}$ ranges from $480 \mu \mathrm{g} / \mathrm{mL}$ in the case of DTAC-ssDNA and DTATfssDNA particles to around $600 \mu \mathrm{g} / \mathrm{mL}$ in the case of DTAB-ssDNA particles.

From the surfactant concentration on the particles and by including the amount of DNA released into the media (see Figure 8 , line plots), the kinetics of the surfactant:DNA ratio on the particles were determined. Figure 10 shows the evolution of the surfactant:DNA ratio as a function of time. 

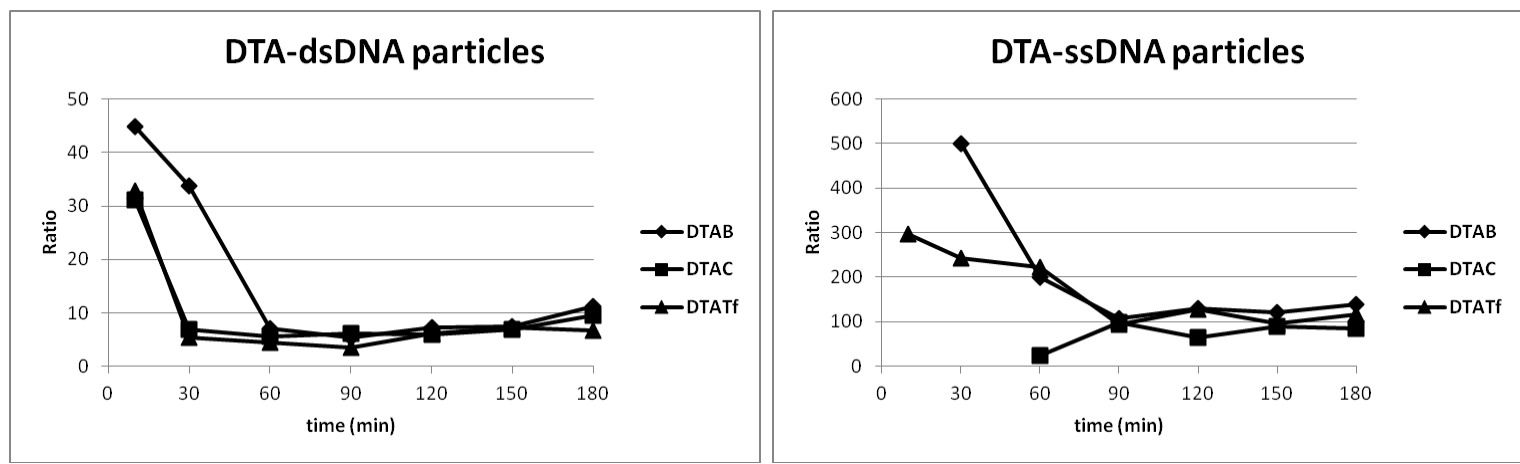

Figure 10. Time course of the ratio of surfactant:DNA release from the DTA-DNA particles.

The $R$ values were at their maximum at initial times, decreasing rapidly after 60-90 min and then reaching a plateau until the end of the experiment. The results obtained suggest that, during the initial stage, the surfactant that is in excess or less attached to the DNA is released. Then, the release of DNA increases as a consequence of the dissolution of the surfactant-DNA complex, remaining almost constant until the end of the experiment.

From these plateau values, information about the stoichiometry of the surfactant-DNA complexes can be deduced. In the case of surfactant-dsDNA particles, the observed ratios in the plateau were around 6,10 and 11 for the DTATf-dsDNA, DTAC-dsDNA and DTABdsDNA systems, respectively. In the case of particles formed with denatured DNA, the calculated ratios in the plateau were above 100. This value has no real meaning, given the presence of DTA-ssDNA particles in the dispersions at the end of the experiment.

The ratios found, always higher than one, are consistent with the protocol of preparation of these surfactant-DNA particles, in which DNA solutions were added dropwise to an excess of gently agitated surfactant solutions.

\section{DISCUSSION}

For an oppositely charged polyelectrolyte-surfactant pair, the simplest type of phase separation in such systems involves the formation of two phases. If there are strong attractive interactions between the two components, the formation of one phase concentrated in both polymer and surfactant and the other diluted in the two components, i.e. an associative phase separation, would be expected. The driving force for this strong association is the electrostatic interaction between the two components, as given by the entropic increase due to the release of the respective counter-ions. A general understanding 
of the interactions between DNA and oppositely charged agents has provided a basis for developing novel DNA gel particles. However, to date, little is known about the influence of the respective counter-ions on this oppositely charged polyelectrolyte-surfactant pair.

The contribution of the counter-ion entropy to free energy association depends on the detailed geometries and charge distributions of the separated and bound macro-ions. The apparent degree of counter-ion dissociation, $\alpha$, also called the degree of micelle ionization, is an important parameter in the physical description of aqueous surfactant solutions. ${ }^{31,32}$ Although ionic surfactants are strong electrolytes below the CMC, i.e. fully ionized, the charge density on the micellar surface is so high that a fraction, $1-\alpha$, of the counter-ions condense onto the surface and reduce the net charge, so $\alpha$ is often only 0.2-0.5. This parameter significantly affects the surface properties of surfactants, such as the CMC, micellar size, reduction of interfacial (or surface) tension, etc. ${ }^{32}$ Colloidal properties, such as substrate binding efficiencies, transport properties and phase transitions (e.g. from spheres to rod-like structures), may also show significant dependencies on $\alpha^{33}$

The characterization of micelles of DTAC and DTAB surfactants as reaction media showed significant differences in their degree of dissociation from the micelle: about $26 \%$ for bromide and about $37 \%$ for chloride in experiments performed at $25^{\circ} \mathrm{C} \cdot{ }^{28,29}$ Recent studies showed values of triflate dissociation ranging from 0.13 to 0.15 for temperatures between 38 and $47^{\circ} \mathrm{C}$. $^{21}$

On the basis of these values, a clear correlation between the degree of counter-ion dissociation for these three surfactants and the corresponding $L E$ values (Figure 1) can be established. Although there are no differences between the $L E$ values of the DTAC and $D T A B$ systems, the most limited dissociation for the triflate counter-ion could explain the lower efficiency observed in the DTATf systems.

Also based on the a values, as well as the character of the triflate anion, which is more hydrophobic than the anions bromide and chloride, the triflate ions on DTATf-DNA complexes could be expected to provide a more hydrophobic environment for the dye NR than halogen counter-ions. Triflate ions, as they have three resonance forms, promote significant water structuring. The extent of water organization has been shown to be responsible for lipid head group dehydration. ${ }^{34,35}$ The observed changes in NR emission argue in favour of these conclusions. 
When used as DNA carriers, understanding the interactions of these DNA gel particles with blood components is crucial for improving their behaviour in vitro. First of all, the haemolytic activity of this DTA-based surfactant was studied as a function of its concentration and the concentration-dependent curves were determined (Figure 5). In these experiments, haemolysis was determined in the presence of a range of surfactant concentrations, which allows us to define the haemolytic potency $\left(\mathrm{HC}_{50}\right)$ of each surfactant.

One drawback of these surfactant-DNA gel particles, in toxicological terms, is the need for a cationic surfactant, which may cause irritation. Our results indicate, however, that the effect of the surfactant can be modulated when administered in the DNA system, unlike an aqueous solution. This modulation is due to the strong interaction between the surfactant and the biopolymer, which leads to a very slow release of the surfactant from the vehicle..$^{36-39}$ Accordingly, although the $\mathrm{HC}_{50}$ values for these three surfactants in an aqueous solution are very close, strong differences were found when the haemolysis kinetics of the corresponding surfactant-DNA gel particles were determined (Figure 6). As the haemolytic character of these surfactants in solution is almost identical, the differences found in the haemolysis responses induced by the different surfactants are related to the capacity to form weaker or stronger surfactant-DNA complexes. It is expected that, for a higher degree of complexation, less surfactant would be released in solution, which could interact with the erythrocytes' membrane.

The differences found between particles prepared with ds- and ss-DNA can be attributed to differences between the two secondary structures. Previous studies of polyelectrolytesurfactant systems, both experimental and theoretical, showed that the linear charge density of the polyelectrolyte, its flexibility and any amphiphilic character will play a significant role for the corresponding interactions. ${ }^{40-46}$ We note that, since the linear charge density of dsDNA ( 0.59 negative charges/ $\AA$ ) is considerably higher than for ssDNA $(0.29$ negative charges/Å) and comes from a simple electrostatic mechanism, dsDNA should interact more strongly with oppositely charged polyelectrolytes. ssDNA is much more flexible than dsDNA, which is quite rigid and characterized by a large persistence length (500 $⿱$ ) ${ }^{42,43}$ In molecular simulations, the role of the flexibility of the polyelectrolyte has been documented in some detail, and it was found that a flexible chain tends to interact more strongly with an oppositely charged macro-ion than a rigid one.

This trend in surfactant-DNA interaction reflects both the release of haemoglobin (degree of haemolysis) and the release of DNA into the media, as a consequence of different dissolution kinetics of the polyelectrolyte-surfactant complexes. Under the experimental 
conditions in which the haemolysis studies took place; dsDNA-surfactant particles were fully dissolved by the end of the experiments. However, ssDNA-surfactant particles remained visible in the dispersion. Here, for the first time, both parameters were determined simultaneously (Figure 8), giving us information about the effectiveness of the two release processes.

The surfactant content on the corresponding surfactant-DNA gel particles was calculated from the haemolysis responses (Figure 9). The surfactant content of these DNA gel particles mostly follows the sequence DTATf < DTAC < DTATB. As mentioned above, the formation of these DNA gel particles is based on associative phase separation, which is entropically driven, determined by the translational entropy of the counter-ions. Accordingly, the differences in surfactant content found in these DNA gel particles can be correlated with differences in the apparent degree of counter-ion dissociation in these surfactants from the corresponding micelles.

\section{CONCLUDING REMARKS}

Dodecyl trimethyl ammonium-based surfactants were used to prepare surfactant-DNA gel particles based on associative phase separation and interfacial diffusion. Here we examined the formation of DNA gel particles by mixing DNA (either single- (ssDNA) or double-stranded (dsDNA)) with different single-chain surfactants whose structure differs only in the corresponding counter-ion. We employed as counter-ions of these surfactants hydrogen sulfate and trifluoromethane sulfonate anions and the two halides, chloride and bromide. The degree of DNA entrapment, swelling/shrinking behaviour, DNA release kinetics and the morphology of the DNA gel particles were studied as a function of both the structure of the counter-ion on the polar head of the surfactant and the secondary structure of the nucleic acid. Analysis of the data indicates that the degree of counter-ion dissociation from the surfactant micelles and the polar/hydrophobic character of the counter-ion are important parameters in the final properties of the particles obtained. The stronger interaction of ssDNA than of dsDNA with amphiphiles suggests the important role of hydrophobic interactions in DNA. For the first time, these DNA gel particles were assessed for haemolysis. Although the haemolytic potency of the various surfactants in solution is very similar, strong differences were found when the haemolysis kinetics of the corresponding surfactant-DNA gel particles were determined. It was found that the stronger the surfactant-DNA interaction, the slower the haemolysis and DNA release kinetics. The surfactant content of the DNA gel particles was calculated from the haemolytic responses, following the degree of counter-ion 
dissociation from the micelle for the different surfactants. By control of the physicochemistry of the components on the DNA gel particles a better assessment on the final properties of these particles can be achieved. In this context, the reduction in the amount of surfactant needed to form surfactant-DNA gel particles will most probably increase the potential of these systems in drug delivery. Recent studies point out why plasmid DNA is much more efficiently transfected than linear DNA using cationic lipids as vectors in gene therapy. ${ }^{47}$ It has been shown that, plasmid DNA, in contrast to linear DNA, is compacted retaining a significant number of counter-ions in its vicinity. This in turn drives to a lower effective negative charge, and therefore a lower amount of cationic lipid is needed. For an effective DNA transfection, the lower the amount of the cationic lipid, the lower is the cytotoxicity. Current research is focused on characterizing the in vitro cytotoxicity of these surfactant-DNA particles.

Acknowledgements. M.C. Morán acknowledges the support of the MICINN (Ramon y Cajal contract RyC 2009-04683) and the Project CTQ2009-14151-C02-02 from Ministerio de Ciencia e Innovación (Spain).

\section{References}

1. W.B. Liechty,D.R. Kryscio, B.V. Slaughter,N. A. Peppas, Chemical and Biomolecular Engineering, 2010, 1, 149-173.

2. D.Costa, M. C. Morán, M. G. Miguel, B.Lindman. Cross-linked DNA Gels and Gels Particles, in DNA Interactions with Polymers and Surfactants, R. S. Dias, B. Lindman, Eds.; Wiley Interscience: New York, 2008.

3. M.C.Morán, M. G. Miguel, B. Lindman, Langmuir 2007, 23, 6478-6481.

4. M. C. Morán, M. G. Miguel, B. Lindman, Biomacromolecules 2007, 8, 3886-3892.

5. M. C. Morán, T. Laranjeira, A. Ribeiro, M. G. Miguel, B. Lindman, J. Dispers. Sci. Technol. 2009, 30, 1494-1499.

6. M. C. Morán, A, Ramalho, A. A. C. C. Pais, M. G. Miguel, B. Lindman, Langmuir 2009, 25, 10263-10270.

7. M. C. Morán, M. R. Infante, M. G. Miguel, B. Lindman, R. Pons, Langmuir 2010, 26, 10606-10613.

8. M. C. Morán, M. G. Miguel, B. Lindman, Soft Matter, 2010, 6, 3143-3156.

9. M. C. Morán, M. G. Miguel, B. Lindman, Soft Matter, 2011,7, 2001-2010.

10. R. Dias, S. Mel'nikov, B. Lindman, M: G. Miguel, Langmuir, 2000, 16, 9577-9583.

11. L. Goracci, R. Germani, G. Savelli. D. M. Bassani, ChemBioChem, 2005, 6, 197-203.

12. A. Dasgupta, P. K. Das, R. S. Dias, M. G. Miguel, B. Lindman, V. M. Jadhav, M. Gnanamani, S. Maiti, J. Phys. Chem. B, 2007, 111, 8502-8508.

13. M. T. Jr. Record, C. F. Anderson, T. M.. Lohman, Q. Rev. Biophys. // 1978, 2, 103-178. 14. K. A. Sharp, R. A. Friedman, V. Misra, J. Hecht, B. Honig, Biopolymers, 1995, 36, 245262.

15. S. A. Palkar, A. M. Lenhoff, J. Colloid Interface Sci. 1994, 165, 177-194.

16. M. P. Sheetz, S. J. Singer, Proc. Natl. Acad. Sci. USA, 1974, 71, 4457-4461. 
17. B. Isomaa, H. Hägerstrand, G. Paatero, Biochim. Biophys. Acta, 1987, 899, 93-103.

18. M. P. Vinardell, M. R. Infante, Comp Biochem Physiol Part C, 1999, 124, 117-120.

19. J. Sambrook, E. F. Fritsch, E. F.; Maniatis, T. Molecular Cloning: a laboratory manual; Cold Spring Harbor Laboratory Press: New York, 1989; Vol. 3, App. C.1.

20. W. Saenger, Principles of Nuclei Structure; Springer-Verlag: NewYork, 1984.

21. F. S. Lima, F. A. Maximiano, I. M. Cuccovia, H. Chaimovich, Langmuir 2011, 27, 43194323.

22. T.I. Smol'janinova, V.A. Zhidkov deceased, G.V. Sokolov, Nucl. Acids Res.1982, 10, 2121-2134.

23. S. Ichimura, M Zama, H. Fujita, Biochim. Biophys. Acta 1971, 240, 485-495.

24. A. R. Peacocke, The interaction of acridines with nucleic acids, in Acridines, R. M. Acheson, Ed.; Interscience Publishers: New York, 1973; pp 723-754.

25. A. Cser, K. Nagy, L. Biczók, Chem. Phys. Lett. 2002, 360, 473-478.

26. G.Hungerford, E. M. S. Castanheira, M. E. C. D. Real Oliveira, M. G. Miguel, H. D. Burrows, J. Phys. Chem. B, 2002, 106, 4061-4069.

27. P. Greenspan and S. D. Fowler, J. Lipid Res., 1985, 16, 781-789.

28. B. L. Bales, M. Benrraou, R. Zana, J. Phys. Chem. B. 2002, 106, 1926-1939.

29. T. M. Perger, M. Bester-Rogac, J.Colloid Interface Sci. 2007, 313, 288-295.

30. M. A. Dobrovolskaia, J. D. Clogston, B. W. Neun, J. R. B. Hall, A. K. Patri,S. E. McNeil, Nano Lett. 2008, 8, 2180-2187.

31. B. Jönsson, B. Lindman, K. Holmberg, B. Kronberg, Surfactants and Polymers in Aqueous Solution; John Wiley: Chichester, 1998.

32. W. M. Gelbart, A. Ben-Shaul, D. Roux, Micelles, Monolayers, and Biomembranes; Springer-Verlag: New York, 1992.

33. M. N. Jones, D. Chapman, Micelles, Monolayers, and Biomembranes; Willey-Liss: New York, 1995.

34. R. D. Koynova, B. C. Tenchov, P. J. Quinn,. Biochim. Biophys. Acta, 1989, 980, 377380.

35. R. M. Epand, M. Bryszewska, Biochemistry, 1988, 27, 8776- 8779.

36. Y. Xu, F. C. Szoha, Biochemistry, 1996, 35, 5616-5623.

37. J. O. Radler, I. Koltover, T. Salditt, C. R. Safinya, Science, 1997, 275, 810-814

38. S. Bhattacharya, S. S. Mandal, Biochimica et Biophysica Acta 1997, 1323, 29-44

39. S. Bhattacharya, S. S. Mandal, Biochemistry, 1998, 37, 7764-7777.

40. T. Wallin, P. Linse, J. Phys. Chem. B, 1997, 101, 5506-5513.

41. T. Wallin, P. Linse, J. Phys. Chem., 1996, 100, 17873-17880.

42. T. Wallin, P. Linse, Langmuir, 1996, 12, 305-314.

43. J. C. T. Kwak, Polymer-Surfactant Systems; Marcel Dekker, New York, 1998.

44. I. Lynch, J. Sjostrom, L. Piculell, J. Phys. Chem. B, 2005, 109, 4252-4257.

45. I. Lynch, J. Sjostrom, L. Piculell, J. Phys. Chem. B, 2005, 109, 4258-4262.

46. I. Lynch, L. Piculell, J. Phys. Chem. B, 2006, 110, 864-870.

47. M. Muñoz-Úbeda, S. K. Misra, A. L. Barrán-berdón, C. Aicart-Ramos, M. B. Sierra, J. Biswas, P. Kondaiah, E. Junquera, S. Bhattacharya, E. Aicart, J. Am. Chem. Soc. 2011, 133, 18014-18017. 


\section{Graphical abstract content}

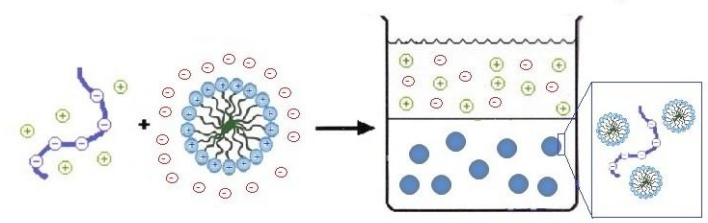

We examined the effect of different counter-ions on the physicochemical and haemocompatible properties of DNA gel particles as controlled DNA delivery systems. 